\title{
Managing Diverse Employees at Starbucks: Focusing on Ethics and Inclusion
}

\author{
Ulla P. Morais, Jacqueline Pena, Kevin Shacket, Lucien Sintilus, Roiner Ruiz, \\ Yesenia Rivera, Bahaudin G. Mujtaba \\ Nova Southeastern University \\ Doi:10.5296/ijld.v4i3.5994ＵRL: http://dx.doi.org/10.5296/ijld.v4i3.5994
}

\begin{abstract}
Workforce diversity is a reality of the modern times for every organization and managing it effectively can lead to a sustainable competitive advantage. The purpose of this paper is to analyze the management of diversity at one of the most admired companies in America, and one of the 100 best companies to work for, Starbucks. We will discuss how managers lead diverse employees in a global environment and what makes this company so unique.

Effective management of diversity is not only employing diverse employees, but learning to appreciate, respect and respond to the needs, values, and beliefs of diverse people and provide a positive work environment. Therefore, we will analyze the general environment and task forces that affect the diversity, as well as the challenges faced by Starbucks managers when managing diverse employees. Furthermore, the impact of diversity on the company performance will be subject of analysis through a value driven perspective. Finally, we will identify some of the best practices for effectively managing diversity and propose some recommendations.
\end{abstract}

Key words: Starbucks, diversity management, workforce diversity, ethics, inclusion, and equality.

\section{Introduction}

One of the greatest challenges for managers today is managing the increase of diversity in the workplace (Mujtaba, 2010). Diversity is defined as "dissimilarities or differences among people due to age, gender, race, ethnicity, religion, sexual orientation, socioeconomic background, education, experience, physical appearance, capabilities/disabilities, and any other characteristics that are used to distinguish between people" (Jones \& George, 2014, p. 135). According to Thompson (2005), organizations who limit the kinds of people they are willing to hire, are limiting also the talent pool from joining the company. Consequently, this discrimination limits the productivity of the organization and predictions for growth and survival (Lundrigan, Tangsuvanich, Wu \& Mujtaba, 2012, p. 43).

As stated by the Level Playing Field Institute in 2008, the most important thing managers can do to promote a better work environment is to treat people fairly and justly based on actual performance and individual merit, irrespective of the employee's race religion, age, gender or sexual orientation (Lundrigan et al., 2012, p. 41). Thus, in order to remain competitive, global companies like Starbucks need to hire people with different skills, races, ages, and genders. In addition, managers need to learn how to manage all employees fairly and involve them in the company culture. In this study, we will identify the strategies used by Starbucks to manage its diverse employees, and analyze its impact on the company success. 


\section{Company Overview}

Starbucks started its business 43 years ago with a single store of a roaster and retailer of whole bean and ground coffee, tea and species. Then, the business thrived and now the company has more than 19,000 retail stores in over 60 countries and has around 160,000 employees (Starbucks, Company profile, 2014; Forbes, 2013). With 13,279 centers located in U.S., Starbucks is the number one of the top ten 10 Largest Coffee Chains in the World (Ektajalan, 2013). Starbucks' mission is "to inspire and nurture the human spirit, one person, one cup and one neighborhood at a time" (Starbucks, Company profile, 2014). In addition, the company takes a holistic approach to ethically sourcing the highest quality coffee.

There is a great balance between profitability and social conscience. Starbucks is considered one of the World's most ethical companies (Ethisphere, 2013). The company uses responsible purchasing practices; supports farmer loans; forest conservation programs; and has been involved in several volunteer programs to help the communities where their stores are located (Starbucks, Company profile, 2014). Furthermore, Starbucks is striving to create a culture that both values and respects diversity and inclusion. To do so, they have integrated diversity and inclusion into the core of their leadership competencies and expect that all leaders practice behaviors that demonstrate inclusion (Starbucks, Diversity and Inclusion, 2014).

The company refers to its employees as "partners" because they consider them as part of the business success. In the Starbucks' Business Ethics and Compliance (2011) focus, diversity is part of the second principle of the company, and it states, "Together, we embrace diversity to create a place where each of us can be ourselves. We always treat each other with respect and dignity. And we hold each other to that standard" (Starbucks, Business Ethics and Compliance, 2011, p. 2).

Similarly, the company is building strategic relationships with organizations and institutions that reflect Starbucks diversity and inclusion values. For instance, Starbucks has relationships with Multicultural Food and Hospitality Association; National Association for the Advancement of Colored People and National Council of La Raza.

Lastly, the company's diversity culture and practices include their suppliers. They believe Supplier Diversity is a smart business decision; therefore, Starbucks supports supplier diversity projects such as National Minority Supplier Development Council and the Women's Business Enterprise National Council. Starbucks states that these practices help them identify and deliver high-quality products and services across all business channels, while driving value and economic development in the communities they serve (Starbucks, Community Service, 2014).

\section{The General Environment}

Demographic forces. The general environment consists of several factors including the socio-cultural aspect (Mujtaba, 2014). The PESTLE analysis is a framework that can be utilized to understand an organization's general environment or macro environment. The acronym stands for: Political, Economic, Socio-cultural, Technological, Legal and Environmental (Oxford, 2012). The economic factor will be discussed later in the reading. Demographic factors involve, "Outcomes of change in, or changing attitudes toward, the characteristics of a population, such as age, gender, ethnic origin, race, sexual orientation, and social class (Jones \& George, 2011). Demographics determine target markets, which will be explored.

Starbucks has built their image to reach the desired target. The majority of their business relies on middle-class and above working adults as well as older students. Since their prices are higher than other competitors, the customers who can afford their coffee are usually of higher income and education. It also provides a place to conduct informal business meetings when there is a lack of infrastructure or when a more relaxed atmosphere is desired. High 
school and secondary education students are often seen studying as well as simply grabbing a cup of coffee with friends. Music is played and light is allowed to flow in to create a chosen atmosphere for customers.

Starbucks practices market-based management methods to thrive in the coffee market. Using the customer's preference depending on profits and losses is one element of being market-oriented (Gable and Ellig, 1993, p. 16). If a product is not doing well, it would get taken away from the market. Starbucks also introduces other products for holiday seasons. Also, Starbucks relies on its corporate values and culture when treating customers (Gable and Ellig, 1993, p. 22). A welcoming ambiance is encouraged and superior customer service is practiced. Amongst others, conducting business in such a manner is conducive with a successful and sustainable company.

In an effort to diversify and broaden their customer base, Starbucks has taken measures to ensure it occurs. "Los Angeles-based real estate development firm, Johnson Development Corp., has opened 42 Starbucks stores in what it calls ethnically diverse and underserved urban areas" (Marques, 2008, p. 254). Also, on a global scale, Starbucks owns stores in over 60 countries and close to 20,000 stores. The company embraces diversity in both customers and employees which concurs with their corporate values and culture. We will now be discussing the economic factors of the general environment.

Economic forces. Economic forces plays a major role on the general health and well-being of a country or world region (Jones \& George, 2011, p. 174). It refers to the nature and direction of the economy in which the business operates. Economic factors have a tremendous impact on business firms. These factors may include the rate of inflation, interest rates, stock market performance, the level of unemployment, and fiscal policies or changes made by the government. It can provide many opportunities and threats for managers. It is important for managers to connect the dots between the external environment and their day-today actions. With this improved information, organizations can engage in bringing forward new ideas that are in line with the challenges and opportunities in the external environment. It is crucial for managers to take the time to analyze the external environment in order to generate better decisions.

The importance of economic indicators to the strategic planning process in any organization is the ability to benchmark economic conditions that contribute to improve profitability, business growth and market size. Starbucks, despite of their inflated prices has been able to create a sense of brand loyalty with an array of loyal followers. As a result, Starbucks has consistently delivered strong financial performance. The company set record revenues of 13.3 billion in fiscal year 2012, a $13.7 \%$ increase from the year before (Sun et al., 2013). Recent acquisitions and expansion efforts will continue to better position Starbucks in the global market and continue its financial success. They opened their first two stores in Vietnam during 2013 and, at times, experienced long lines as people wanted to taste their first coffee of the brand they had heard of through movies and television shows for so many years.

At Starbucks, their market-based management method strives to create a culture that values and respects diversity and inclusion (Starbucks, Working at Starbucks, 2013). Their goal is to build a diverse workforce, increase competencies, shape a culture of inclusion and develop a diverse network of suppliers. Koch stated, "A company's values and culture can guide employee's actions in ways that advance the common mission" (Gable and Ellig, 1993, p. 22). Starbuck's welcoming work environment has encouraged partners to engage with one another and make Starbucks a place they look forward to working each day. As a result, it has brought much success into their business.

Another facet that Koch mentioned is that organizations also can possess comparative advantages, because groups of people can jointly develop capabilities to do certain things particularly well (Gable and Ellig, 1993, p. 11). Starbucks, for example, has excelled by 
developing purchasing agreements and sourcing from multiple regions to protect themselves from environmental, political, to economic factors affecting the company and their ability to obtain their coffee bean crop. Additionally, Starbucks operates in a monopolistically competitive market structure in which they have been able to maintain a control over their inflated prices.

With usage of the Starbucks logo, quality, and various trademarks, they differentiate their coffees from their competitors. Starbucks prides itself on being completely different from any other coffee house and its competitors, which is a reason why they became so successful. The company's strategy is to focus on their core competencies to differentiate themselves has made Starbucks into a coffee powerhouse.

\section{The Effect of Customers and Competitors on the Company Management}

Customers. Every organization needs customers if it's going to survive. Even not-for-profit organizations must have "customers" who use its services or purchase its products (Coulter, 2005). One functional strategy managers can use to get close to customers and understand their needs is customer relationship management. Customer relationship management is a technique that uses information technology to develop an ongoing relationship with customers to maximize the value an organization can deliver to them over time (Jones \& George, 2014).

The effect of customers in the company management has a significant impact on the organizational development and may be streamlined to organizational performance of the organization as a whole. To satisfy the needs of diverse customers, Starbucks has adopted a market structure which is responsible for the needs of their customers and even allows them to act flexibly in making decisions in response to their changing needs. "Starbucks seeks to connect first with employees and second with customers," said their CEO Howard.

Many of the values held by the Starbucks corporation business model are shared by consumers and adapted by closely watching organizations. One value that stands out for the company is the community support. According to Starbucks Corporation (2008), Starbucks continues to satisfy employment needs and provide excellent customer service. Starbucks' customers want each Starbucks location to be unique to its local environment and for it to recognize them as individual customers.

Needless to say, it is quite a challenge for Starbucks to be so highly standardized that their product remains the same, but flexible enough to make each store unique to its local clientele. How does Starbucks accomplish this? Part of the answer is through the company's organizational structure and how jobs and tasks are coordinated between their partners (Starbucks Corporation, 2008).

Competitors. Starbucks is one of the leading American coffee companies that is known across the world. When most Americans think coffee they naturally think Starbucks. The brand and image that Starbucks has created for itself has allowed for it to have a strong and loyal customer base that leaves its competitors scratching their heads coming up with ways to catch up. In the American coffee market, Starbucks has had to compete with other corporations such as Einstein Bagels, Dunkin' Donuts, McDonald's, and Nestle. For many years, Starbucks has been able to break away from its competitors and is doing an excellent job of standing out amongst its competition.

Starbucks has been able to keep the edge on its competitors for several different reasons. One of those reasons is its specialization in their assortment of beverage selections. Most of its competitors focus their business on other items that are not beverages such as Dunkin' Donuts specializing in donuts, Einstein Bagels in bagels, etc. Starbucks is one of the first of its kind to primarily be a coffee shop. While they do sell other products such as baked goods, teas, and other items, their specialty is in their coffee and the vast variety of beverages it 
can offer to its consumers that are Starbucks specific. By staying on this track, Starbucks is destined to stay ahead of the pack in the American coffee market for several years to come.

\section{Is Diversity a Challenge or a Benefit?}

Diversity in the workforce is an extremely powerful tool. It promotes a new way of thinking. By having a diverse workforce, you allow for a melting pot of cultures, ideas, and values. In teams, often times when a problem arises the team looks for different ways to solve that given problem. It is easier for a more diverse team to arrive at a viable solution to the problem, than it is for a team that is much less diverse. Having a diverse group, allows for different cultural educational and ethical backgrounds to come together and think about issues in a new and fresh light. It has been scientifically proven that "Human capital diversity, such as educational diversity, has been found to be related to team creativity" (Han, Han \& Brass, 2014, p. 55). Therefore, it is extremely important to stress the importance of effectively incorporating different diversities in the workplace, and also understanding the most appropriate ways to manage such a workforce; something that Starbucks will most definitely continue to encounter.

At times, companies have labeled diversity as a challenge. The perception of diversity as a hindrance to an organization comes from negative stories in the media about certain topics such as discrimination lawsuits, affirmative action quotas, and so on. While these stories heard in the media can be a bit exaggerated, there are situations that exist in daily business life. The difference is that the reason those challenges arise are from either disparate treatment of employees or applicants, or from a lack of understanding of the importance of diversity in a workplace.

"The way they can be overcome this is by having a firm grasp in understanding diversity, what it represents, what it can do and what the challenges are...Many negatives can arise if you don't understand how to manage diversity" (Goessi, 2008, p. 1). By carefully understanding the importance of diversity, an organization has the power to transform their organization into a much more powerful company than it was before. By bridging the gap between different minorities, tearing down the stereotypes, and understanding that each individual person has something special, creative, and unique that they can bring to the table, organizations now have an unstoppable creative force. Not only does diversity bring much more creativity to the table, but it also allows for a greater demographic to be reached.

If a company had an only all Anglo-American male workforce, they could potentially lose out many of their customers. The reason for this would be that certain minorities, such as women, African-American, Hispanics, Asians, etc. would feel as they cannot relate to that brand. They could often feel a sense of intimidation and lack of comfort. By having a workforce comprised of several different backgrounds, an organization allows its customers to relate to them and gives them a sense of belonging to a product or service before they are even actual buyers.

Failing to understand the impact on diversity raises at least three major issues (Goessi, 2008, p. 1). The most obvious of which is lawsuits. Based on Title VII of the Civil Rights Act of 1964, there are certain protected classes such as race, gender, religion, and national origin; discriminating against an employee or applicant based on these characteristics, would be grounds for a lawsuit. The other two less obvious issues that arise from failing to understand the impact of diversity on an organization are high turnover rates and absenteeism. The reason for both of these is quite obvious and that is a decrease in employee morale. When employee morale decreases, so does employee engagement, and conversely so, when employee engagement decreases, absenteeism and turnover rates increase. This is not only a major problem because it affects the employees on a psychological and emotional level, but also because it economically puts a major financial hardship on the organization. The cost of 
training employees can be quite costly, and similarly so are the costs in recruiting effective team members to fill vacancies within the organization. It is therefore extremely important to keep employees engaged and aware of the importance and impact diversity has on an organization.

Much of what has been discussed can seem overwhelming for some organizations, and in part can be responsible for organizations viewing diversity as a challenge more than a benefit. The view an organization has on diversity is quite similar to an approach that can be taken when discussing change management. Understanding that there can be great value added to an organization by having a diverse workforce is the first step. Management should attend and also encourage employees to attend diversity sensitivity courses, and educate themselves along with their staff on the importance and benefits that diversity can bring to the workplace. By having a solid understanding of diversity and the positives that it can bring to enhance the organization, there is less likelihood for a negative response.

One organization that is not foreign to the benefits of diversity is Starbucks. Starbucks not only is an Equal Opportunity Employer, but they even have special programs such as their Supplier Diversity Program, in which they reach out to do business with minority-owned businesses and also with several organizations that promote workplace diversity. Troy Alstead, CFO-CAO for Starbucks Coffee Company stated, "We believe Supplier Diversity is a smart business decision. It helps us identify and deliver high-quality products and services across all business channels, while driving value and economic development in the communities we serve" (Starbucks.com, Supplier Diversity Program).

Starbucks is a prime example of an organization that goes above and beyond the call of duty in regards to accepting and understanding the power of diversity. This is extremely evident in their mission statements, organizational vision, and not to mention profitability. An organization of this magnitude would not have gotten to where it is today without the deep understanding of what diversity can accomplish.

\section{Critical Managerial Roles}

Managers play a critical role in the process of effective management of diversity. Managers can influence others to support diversity through their positions of status. Research on social influence supports such a link: People are likely to be influenced and persuaded by others who have high status (Jones \& George, 2014). Furthermore, managers can either promote effective management of diversity in the workplace or dismantle such efforts. Managers should be committed to bring diversity to ensure all members of their organization believe their diversity-related efforts are valued. Critical components in the success of diversity management initiatives are top management commitment and rewards for the support of diversity. In addition, there are two other main factors that convey why managers are critical in the process to effective management. First, minority groups are often at a slight disadvantage due to how others in the organizations perceive them (Jones \& George, 2014). Moreover, a substantial proportion of minorities feel they would receive better care if they were of a different race or ethnicity (Collins et al., 2002).

Secondly, research has suggested that slight differences in treatment can accumulate and result in major disparities over time. It is very important for managers to prevent any disparities in treatment and outcomes due to irrelevant dissimilarities such as race or ethnicity. Within this paper, readers will learn ways managers can ensure that diversity is effectively managed through three types of managerial roles: interpersonal, informational and decisional. In addition, Starbucks managers is analyzed to see how they deliver their goal to build a diverse workforce, increase competencies, shape a culture of inclusion and develop a diverse network of suppliers. 


\section{The Ethical Imperative to Manage Diversity}

Starbucks is known globally for its acceptance of different cultures. The company states, "Starbucks actively creates and promotes an environment that is inclusive of all people and their unique abilities, strengths and differences, and promotes diversity as a strategic and competitive business advantage for the company" (Starbucks Business Ethics and Compliance, 2011). Such mentality allows them to thrive on different cultures enough to see it as a competitive edge.

Managers are responsible for supervising partners who hold different work ethics and originate from different cultures. Before all, actions must be made in accordance with the Civil Rights Act of 1964 Title VII (EEOC, 1964, section 702). Partners must be treated equally and without prejudice. Religion must be taken into consideration, as certain holidays do not correspond with U.S. holidays. For example, Seventh Day Adventists can request Saturday off as his or her Sabbath and if not cause undue hardship on the business, the employer is obligated to accommodate the employee (ACLJ, 2012, para. 12). Being knowledgeable regarding the laws and regulations is a requirement for all managers and professionals.

An ability that managers should possess is understanding of the partner's limitations and beliefs. Partners should not be forced to do activities or speak in a manner that would contradict their values. Following that behavior would create a more personal yet respectful relationship between the partner and manager. In order to foster such a relationship, various strategies that can be taken to create a stronger bond are discussed here.

Cultural competence is essential in managing diversity effectively. An ethical aspect would be to treat each employee justly regardless of ethnicity, religion, etc. One method to gain cultural competence would be to self-assess using a cultural competence tool. Another activity would be to organize events to socialize with the employees and understand them better. To show how Starbucks is ethical not only to their partners but also their suppliers, customers, and the environment, the company started CAFÉ Practices. It is a program that, "Sets basic social, environmental and quality criteria, which Starbucks verifies" (Elder, Lister, \& Dauvergne, 2014, p. 80).

"Culture is enacted principally by a company's upper management, which in turn influences the behavior of managers and its employees throughout the organization" (Hinkin \& Tracey, 2010, p. 160). At Starbucks upper management has adopted a culture that embraces diversity. It allows partners to have a compressed week, which is the option to work more hours in a day to have fewer workdays. Also, scheduling works in flextime that accepts unlimited arrangement of schedules in order to meet a partner's schedule (Hinkin \& Tracey, 2010, p. 164). With these options, Starbucks has the opportunity to hire different individuals with diverse schedules. "It is the opinion of the Starbucks' president of global diversity, May Snowden, that certain groups do not get enough opportunities to take their legitimate place in the workforce (Corkery, 2005). Being aware of that, Starbucks is now reaching out to people with disabilities, both as employees and as customers" (Marques, 2008, p. 253). Following such thought has encouraged managers to employ diverse partners. For example, Cindy Rogers who uses personalized tactile pads on the cash register because she has lost most of her vision (Marques, 2008, p. 253). Also, Corey Lindberg who is a deaf senior business systems analyst (Marques, 2008, p. 253).

Starbucks' managers must take ethical values and practices into consideration when managing partners. Employers cannot be discriminated on the basis of race, color, religion, sex, or national origin. During the hiring process, both managers and partners have active roles in selecting future partners (Hinkin \& Tracey, 2010, p. 165). This ensures multiple opinions and less bias during the selection process. Starbucks has taken the necessary provisions in ensuring managers have been well trained in handling partners with different cultures. The 
company has excelled and should continue to view this attribute as a competitive advantage. Next, we will be discussing factors that can have an impact on the perception of managers.

\section{Factors that Influence Managerial Perception}

In the managerial arena, there are a variety of factors that affect managerial perceptions. It is important for managers to be in tune with many aspects of their businesses. Some aspects of business include evaluating employee effectiveness, monitoring customer satisfaction, and overseeing the business's overall success. Within these arenas are multiple factors that affect how managers perceive the information that they are receiving. In other words, data about productivity is one source of information, but another aspect of the business, perhaps a cost factor, might influence the way in which the manager perceives the quality of information about the process that they are trying to control.

Over time, researchers have developed a series of mental models which they use to gauge various aspects of how managers perceive their business environment. A study of some of these models demonstrates how various situations affect perception. One such study looks at how managers make decisions regarding the risk involved with pioneering business ventures (Benedetto \& Song, 2008). Evidence has demonstrated that culture and country of origin play a large role in perceptions. The theoretical framework suggested that managers base many of their decisions on the "reality" of the situation. So culture of origin plays a role in determining what situations are more realistic in and out of the context of the managers' personal background (Benedetto \& Song, 2008).

Following the factor of culture of origin, a similar study looks at how managers make specific decisions. In this study, the researchers further explore the literature on mental models and how managers make decisions based on their own personal beliefs (Song, Zhao, \& Benedetto, 2013). Following the idea that managers establish their own personal reality based on cultural background, the study explores the implications of personal beliefs over the use of generally accepted business practices. The researchers asserted that an understanding of a manager's cultural background plays a large role in establishing their methods for decision making (Song, Zhao, \& Benedetto, 2013). This is a significant factor when exploring the factors that influence managers' perceptions.

In addition to cultural elements of the mental model, other researchers have determined that some managerial decisions are based on whether or not an individual perceives a certain element of the decisions making process to be important or not. The factors that guide a manager's perception of importance have a lot to do with the managers understanding of the current market, and the firm's strengths and weaknesses in that market (Tashman \& Raelin, 2013). The researchers asserted that managers make decisions based on power distance, legitimacy of the need, market urgency, and personal interests to name a few. Of these factors, each plays an integral role in how decisions are made.

Interestingly, following the idea that managers' perception is important to employment outcome, Schuh and Zhang (2013) explore the reciprocal circumstance in which employees' perception of a manager's leadership style has a great effect on the success of the venture. The study explored the managers' transformational leadership style, and the various outcomes associated with perceptions. Some employees perceived a shift in their managers' style as a threat to their employment status, while others considered this a positive attribute where they were rewarded by their manager's attention.

The researchers determined that based on a variety of transformational characteristics, employee perception of managers could be assessed with predictable outcomes. Those managers who were perceived with a more authoritarian style were met by resistance from employees, while those with a more authoritative style were embraced as moral leaders. Those management styles where perception was linked to morality had higher employee retention 
rates than those who did not. Additionally, productivity was shown to increase when employees felt they were working in a more moralistic environment which was congruent with their own belief systems (Schuh \& Zhang, 2013).

These various bodies of research culminate in the understanding that outlining the factors to perception is a complex process. There are many contributions that affect an individual's perceptions and realities, and managers should be chosen for certain jobs accordingly. One would consider that with a knowledge of how an individual's culture affects his/her decision making, managers can be chosen to do jobs that their cultures of origin suite them for. In the case of Starbucks, it is important for business managers to originate from cultures that are congruent with the company's own culture of origin so that decisions are made with values that are congruent with the corporate mission and success of the organization in mind.

\section{Impact of Diversity on the Company Performance}

According to some researchers, diversity may produce a negative and positive effect; it can simultaneously produce conflict and employee turnover as well as more creativity and innovation (Kochan et al., 2003, p. 5). There are factors that influence the positive or negative impact of diversity in the workplace, such as organization's strategy, culture and human resources practices. Therefore, if the organization has an open communication culture and flexible environment, which facilitates diversity, the group performance will be positive. In contrast, if the organization environment is inhibited, with close communication and strict culture, diversity will have a negative impact on the group performance. For instance, at Starbucks, the goals of the diversity and inclusion team consist of building a diverse workforce, increasing cultural competencies, influencing the culture of inclusion and developing a diverse network of suppliers (Starbucks, Diversity and inclusion, 2014).

In the organizations where the HR department provides policies and training programs in diversity to enhance the skills of management and group members, diversity will be an advantage, and it will result in positive performance outcomes (Kochan et al., 2003, p. 7). Starbucks training program is very broad. The company provides general training, development modules, management training programs, as well as diversity courses. The diversity courses include Diversity Learning Journey, which is a course with separate modules that can be conducted as individual workshops and Bias-free Interviewing Workshops, which prepare their managers and recruiters for the hiring process. These training courses allow the company to foster a climate of inclusiveness, cooperation and productive relationships between its "partners" and with its suppliers (Starbucks, Corporate Social Responsibility, 2003).

After analyzing the demographics of the workforce today, one can find a melting pot of different ages, genders, religions, among other differences. For example, it is noticed that there is a shift on the aging of the workforce. There are more aging workers reaching retirement age; thus there is a shortage of young workers. Likewise, it is more common for the youth to be a leader, as a result, managers have to create tools to manage and balance that differences and gap. In large companies, managers can use older employees to coach younger employees. This way they will demonstrate an appreciation to deserving team members which is good for the morale of the entire team (Lundrigan, Tangsuvanich, Wu \& Mujtaba, 2012, p. 41).

At Starbucks, the majority of employees working at stores are young; thus, some conflicts can occur when the manager is also young, and there are some older workers within the team. For example, an older former Starbucks' barista was a victim of age discrimination in a store, in Kansas City. This employee had some conflicts with her young supervisor who felt intimidated by her and at the end she was fired (Bunny, 2007). Some managers have difficulties in managing older employees on their team because they feel intimidated. Therefore, some age discrimination can occur and lead to job dissatisfaction. Although the 
organization's culture is to respect and embrace diversity, it is clear that this culture is not practiced by all employees at all the stores. Thus, it is important for managers measuring their actions before taking decisions because it could have bad implications in the future. Managers should consider all employees at the same level and treat them equally. Managers should know what they value and weight their value in short and long term horizon. This incident with that older employee could lead to bad company image and affect the recruitment process. As a result, Starbucks will have lack of diversity in their workforce and lose its competitiveness. Additionally, older customers would not have the opportunity to be served by older employees who could provide them special attention. Therefore, it is every employee's job to seek out what adds value and ensure success and eliminate the value destroyers by putting people in proper jobs and processes (Pohlman \& Gardiner, 2000, p. 9).

In regards to gender diversity, there is an increasing number of women in the workforce and the management positions. In order to optimize employees' satisfaction and increase productivity, leaders must respect gender diversity and endeavor to assign each person to tasks that best suit his or her strengths (Lundrigan et al., 2012, p. 46). Starbucks is one of the companies that foster women and minority to top positions. For instance, $24 \%$ of top corporate officers are women. For all executives, vice presidents and above, women represent $31 \%$, and for people of color it is $13 \%$. These percentages are higher than the average for other Fortune 500 companies, which is about $15 \%$ for women and about 3-to-5\% for people of color. However, there are many organizations that have in place a glass ceiling practice, which is a metaphor alluding to the invisible barriers that prevent minorities and women from being promoted to top corporate positions (Jones \& George, 2014, p. 136). Hence, the respect for women in leadership positions has a positive impact on the internal and external organizational environment and will bring value over time. Starbucks "partners" increase their motivation, productivity and loyalty toward the organization. Likewise, the company will attract talented candidates who valorize that company's culture, and customers and suppliers enjoy coping with a diverse workforce. Equally, unions will be satisfied because they value people being treated with dignity and respect companies who give employees opportunity to be promoted.

Starbucks uses the balanced scorecard to evaluate workforce representation, as well as the progress in supplier and vendor diversity. The company spends millions of dollars doing business with Women- and minority owned businesses (Forsythe, 2005). These wise and conscious business practices have a positive impact on the company's image and in its value over time. As a result, the company is respected, socially responsible, admired and keeps its position in the ranking of one of the best companies to work for.

\section{Best Practices to Manage Diversity}

Today's best leaders/managers realize that diversity sparks innovation, lead to better decision making, and spurs growth (Daft, 2011). According to Koonce (2001), effective managers are aware that certain skills are necessary for creating a successful, diverse workforce. First, managers must understand discrimination and its consequences. Second, managers must recognize their own cultural biases and prejudices (Koonce, 2001). Diversity is not about differences among groups, but rather about differences in individuals. Each individual is unique and does not represent or speak for a particular group. And therefore, managers should be willing to change the organization if necessary (Koonce, 2001). Organizations need to learn how to manage diversity in the workplace to be successful in the future (Flagg, 2002). There is no single recipe for success. Diversity management success mainly depends on the manager's ability to understand what is best for the organization based on teamwork and the dynamics of the workplace. According to Roosevelt (2001), managing diversity is a comprehensive process for creating a work environment that includes everyone. When creating a successful diverse workforce, an effective manager should focus on personal 
awareness. Both managers and associates need to be aware of their personal biases. Therefore, organizations need to develop, implement, and maintain ongoing training because a one-day session of training will not change people's behaviors (Koonce, 2001).

Losyk (1996) outlined that managers should know managing diversity is more than equal employment opportunity and affirmative action (Losyk, 1996). Managers should expect change to be slow, while at the same time encouraging change (Koonce, 2001). Research shows that one of the best practices for managers to manage diversity in the workplace is to execute a diversity plan. This involves mapping out a way to create an appreciation for diversity in all employees in their office. Other essential tools to manage workplace diversity can be conflict resolution which is very challenging in the workplace. Managers should have the ability to handle conflict and disagreements that arise because of cultural differences. Managers should take into account those problems as to not decrease productivity in the organization. Manager should be objective and fair as well. When examining a disagreement, try to be fair and accurate in the process. Communication may be one of the best ways to manage workforce diversity. It is good sometimes to encourage employees to share concerns as they arise. Try to keep an open door policy. Managers must be open with their employees so that they feel comfortable to come to you with questions and concerns about work-related issues.

At Starbucks, they strive to create a culture that values and respects diversity and inclusion. They expect to be a leader in diversity and inclusion, from their partners in the field to their senior leadership teams. To help make their goals a reality they have integrated diversity and inclusion into the core of their leadership competencies. They expect that all leaders within Starbucks practice behaviors that demonstrate inclusion. They will reach out to leverage diverse points of view, talents and capabilities. "The goals of the diversity and inclusion team include building a diverse workforce, increasing cultural competencies, shaping a culture of inclusion and developing a diverse network of suppliers" (Starbucks, 2014).

Diversity and inclusion are today a central part of Starbucks's corporate-responsibility strategy for all retailers (Mujtaba and Franklin, 2007). They embrace diversity as an essential component in the way they do business. Perhaps the most impressive statistics involve the company's continuing commitment to its supplier-diversity program, which tracks spending with minority- and women-owned business.

Personal Qualities for Leading Diverse People. Research has shown that four characteristics have been identified for leading diverse people in the workplace. First, a personal, long-range vision that recognizes and supports a diverse organizational community in which managers should have long-term plans to include employees of various ethnic and cultural groups, races, ages, and so on at all levels of the organization. In addition, they express the vision through symbols and rituals that reinforce the value of a diverse workforce. Second, a broad knowledge of the dimensions of diversity and awareness of multicultural issues in which managers need a basic knowledge of the various dimensions of diversity. They should put this knowledge into action through the use of inclusive language and showing respect for differences. Third, an openness to change themselves in which managers in diverse organizations encourages feedback from their employees, accepts criticism, and is willing to change their behavior. It is managers' behavior that has the most impact on whether diversity is truly valued within the organization. And finally, mentoring and empowerment of diverse employees in which managers take an active role in creating opportunities for all employees to use their unique abilities. Leaders should offer honest feedback and coaching as needed, and they should reward those in the organization who show respect to all individuals (Daft, 2011).

Action Memo for managing diversity. Leaders and managers can hire and promote people from diverse cultures and with diverse human characteristics. They can use organizational diversity to improve creativity and decision making, better serve customers, and 
enhance organizational flexibility (Mujtaba and Cavico, 2013). They may appreciate differences among people but shed stereotypes and prejudicial attitudes. They should avoid discrimination and view differences among people as positive or neutral. One of the most important things that can be beneficial for workforce diversity to fight ethnocentric attitudes, create an environment in which people value diverse ways of thinking, dressing, or behaving, and break down the barriers of unequal expectations, stereotypes, unequal pay, and the glass ceiling. Managers may choose to employ an interactive, collaborative leadership style (Daft, 2011). In an effective organization, like Starbucks for example, managers develop personal relationships with workers and make everyone feel like an important part of their success.

\section{Conclusion and Recommendations}

In conclusion, a comprehensive review of the predominating literature regarding managing diverse populations of employees illustrates how important it is to consider a wide variety of managerial approaches when working with a diversified employee base. Some of the factors most importantly considered throughout this investigation include the demographic and economic forces that foster healthy environments for employment; the ways in which customers and competitors affect how the company is managed; how diversity challenges and benefits the corporation; the critical roles of managers and the ethical imperatives that drive them; and the factors that influence perception.

A brief summation of the literature provides us with an explanation of the mechanisms at work, and help us better understand the implications for managing diverse employees. Most important of all the factors is for managers to be patient and understanding of their employees' diverse backgrounds. The research and methods developed for managers to increase their ability to balance diverse workloads so they can run the organization in ways that benefit not only customers, but also employees. A subsequent result of learning to accommodate diverse employees not only improves working conditions for employees, but more so increases the company's overall appeal when demonstrating multicultural competencies.

Although Starbucks has been fostering diversity and inclusion practices within their workplace, there is a challenge to change mentalities, values, beliefs and biases against differences among people. Therefore, as a recommendation for Starbucks to further enhance its diversity climate at the workplace, we suggest for the company to reinforce its training programs for all employees; mix the age of work teams in the store to balance their skills and experiences and provide accommodation for employees with disability or other tools to enhance employees' efficiency. In addition, Starbucks should reward and recognize those employees who best promote and manage diversity within the company. Overall, the company's culture should be flexible, positive, open and unique to attract and retain people. Likewise, the culture should be strong and respectful in order to encourage commitment.

On the other hand, providing mentors to develop women and minority to leadership positions is a practice for successful companies that embrace diversity and want to ensure that employees are prepared with the right skills and competencies to handle higher positions.

In order to excel in diversity practices, companies should go beyond the Equal Employment Opportunities law, and other similar laws that protect diverse employees. With this in mind, companies and all employees need to have an open mind and be willing to learn every day with each other in order to promote a positive, safe, productive and successful workplace.

Wise leaders will focus on performance regardless of any gender bias, race, religion or sexual orientation in order to increase company competitiveness. Leaders have to treat everybody fairly and lead by example so employees follow them, and create a positive workplace for everybody. 


\section{References}

ACLJ. (2012). Working on Sabbath Sunday. Retrieved from aclj.org/workplace-rights/working-on-the-sabbath-sundayL

Benedetto, A., Song, M. (2008). Managerial perceptions of global pioneering advantage: Theoretical framework and empirical evidence in the US and Korea. Industrial Marketing Management. 37, 863-872. doi:10.1016/j.indmarman.2008.02.014.

Bunny. (2007, September 13). Bunny's Story. Starbucks Barista Victimized by Age Discrimination .Industrial Workers of the World (Web log post). Retrieved from http://www.iww.org/node/3649

Coulter, M. (2005). Strategic Management in Action. (3th ed.). Upper Saddle River, New Jersey, 07458.

Collins, K. S., Hughes, D. L., Doty, M. M., Ives, B. L., Edwards, J. N., \& Tenney, K. (2002). Diversity Communities' Common Concerns: Assessing Health Care Quality for Minority Americans. The Commonwealth Fund. Retrieved from http://www.commonwealthfund.org/Publications/Fund-Reports/2002/Mar/Diverse-Co mmunities--Common-Concerns--Assessing-Health-Care-Quality-for-Minority-Ameri cans.aspx\#citation

Daft, R. L. (2011). The Leadership Experience. ( $5^{\text {th }}$ ed.). South-Western, Cengage Learning.

EEOC. (n.d.). Title VII of the Civil Rights Act of 1964. Retrieved from http://www.eeoc.gov/laws/statutes/titlevii.cfm

Elder, S. D., Lister, J., \& Dauvergne, P. (2014). Big retail and sustainable coffee: A new development studies research agenda. Progress in Developmental Studies, 14(1), 77-90.

Ektajalan. (2013, June 20). Top 10 Largest coffee chains in the world. List Dose. Retrieved from http://listdose.com/top-10-largest-coffee-chains-in-the-world/

Ethisphere. (2013). 2013 World's most ethical companies. Retrieved from

http://m1.ethisphere.com/wme2013/index.html

Flagg, A. (2002, February 8). Managing diverse workgroups successful. United Behavioral Health. Retrieved from http://www.ubhnet.com.

Forbes. (2013, May). Starbucks. World's Most Valuable Brands. Retrieved from http://www.forbes.com/companies/starbucks/

Forsythe, J. (2005). Starbucks Coffee Company. Leading with diversity. The New York Times. Retrieved

from

http://www.nytimes.com/marketing/jobmarket/diversity/starbucks.html

Fortune. (2013). 100 Companies to work for. CNN Money. Retrieved from

http://money.cnn.com/magazines/fortune/best-companies/2013/list/?iid=bc_sp_full

Gable, W. and Ellig, J. (1993). Introduction to market-based management. Fairfax, VA: Center for Market Processes.

Goessi, L. (2008). Challenges of Diversity in the Workplace. InsideBusiness30. Retrieved from

http://www.insidebusiness360.com/index.php/challenges-of-diversity-in-the-workplac e-23210/

Han, J., Han, J., \& Brass, D. J. (2014). Human capital diversity in the creation of social capital for team creativity. Journal of Organizational Behavior, 35(1), 54-71.

Hinkin, T. R, \& Tracey, J. B. (2010). What makes is so great?: An analysis of human resources practices amongst Fortune's best companies to work for. Cornell Hospitality Quarterly, (51)2, 158-170. doi: 10.1177/1938965510362487

Jones, Gareth R. and George, Jennifer M. (2014). Contemporary Management, $8^{\text {th }}$ edition.

McGraw Hill, New York. 
Jones, G. R., \& George, J. M. (2011). Managing in the global environment. Contemporary Management. New York, NY: McGraw Hill.

Kochan, T., Bezrukova, K., Ely, R., Jackson, S., Joshi, A., Jehn, K., Leonard, J., Levine, D., and Thomas, D. (2003). The effects of diversity on business performance: Report of the diversity research network. Human Resource Management, 42(1), 3-21. Doi: $10.1002 / \mathrm{hrm} 10061$

Koonce, R. (2001). Redefining diversity: it's not just the right to do; it also makes good business sense. Training and Development, 12(12), 22-32.

Losyk, B. (1996). Managing a changing workforce: Achieving outstanding Service with today's employees. Davie, FL: Workplace Trends Publishing.

Lundrigan, M., Tangsuvanich, V., L., Wu, S., and Mujtaba, B.G. (2012). Coaching a diverse

workforce: The impact of changing demographics for modern leaders. International Journal of Humanities and Social Science, 2(3), 40-48.

Marques, J. F. (2008). Spiritual performance from an organizational perspective: The Starbucks way. Corporate Governance, 8(3), 248-257. doi: $10.1108 / 14720700810879141$

Mujtaba, B. G. (2014). Managerial Skills and Practices for Global Leadership. ILEAD Academy: Florida.

Mujtaba, B.G. (2010). Workforce diversity management: Challenges, competencies and strategies (2nd ed.). ILEAD Academy: Florida.

Mujtaba, B. G. and Franklin, E. (2007). A retailer's steady growth strategy: should Publix stay national or go global? Journal of Business Case Studies, 3(4), 33-42.

Mujtaba, B. G. and Cavico, F. J. (2013). Corporate Social Responsibility and Sustainability Model for Global Firms. Journal of Leadership, Accountability and Ethics, 10(1), $58-75$.

Oxford Learning Lab. (2012). PESTLE - macro environment. Retrieved from: http://www.oxlearn.com/arg_Marketing-Resources-PESTLE---Macro-EnvironmentalAnalysis_11_31

Pohlman, R.A. \& Gardiner, G.S. (2000). Value Driven Management, How to Create and Maximize Value Over Time for Organizational Success. New York: Amacom.

Roosevelt, T. R. Jr. (2001). Elements of a Successful "diversity" process. The American Institute for Managing Diversity. Retrieved from http://www.aimd.org/articles/elements.html.

Schuh, S., Xin-an, Z. (2013). For the good or bad? Interactive effects of transformational leadership with moral and authoritarian leadership behaviors. Journal of Business Ethics. 116, 629-640. DOI: 10.1007/s10551-012-1486-0

Song, M., Zhao, Y., Benedetto, C. (2013) Do perceived pioneering advantages lead to first-mover decisions? Journal of Business Research. 66, 1143-1152. doi:10.1016/j.jbusres.2012.03.010

Starbucks. (2003). Living our values. Corporate Social Responsibility. Fiscal 2003. Annual Report.

Retrieved

from

http://globalassets.starbucks.com/assets/e31d4604b78141bfb13172aa5fd67cfa.pdf

Starbucks. (2011) Business ethics and compliance. Retrieved from: globalassets.starbucks.com/assets/eecd184d6d2141d58966319744393d1f.pdcom

Starbucks. (2014). Community Service. Retrieved from http://www.starbucks.com/responsibility/community/community-service

Starbucks. (2011). Our Starbucks mission. Business ethics and compliance. Standards of 
Business

Conduct.

2014, Vol. 4, No. 3

from http://globalassets.starbucks.com/assets/eecd184d6d2141d58966319744393d1f .pdf

Starbucks. (2013). Working at Starbucks. Retrieved from http://www.starbucks.com/careers/working-at-starbucks

Starbucks. (2014). Diversity and inclusion. Retrieved from http://www.starbucks.com/responsibility/community/diversity-and-inclusion

Starbucks. (2014). Starbucks company profile. Retrieved from http://www.starbucks.com/about-us/company-information

Starbucks. (n.d.). Supplier Diversity Program. Retrieved from http://www.starbucks.com/responsibility/diversity/suppliers

Sun, T., Alvarez, K., Yu, P., \& Mlot, B. (2013). Consumer Discretionary: Starbucks Corporation. Krause Fund Research. Retrieved from http://tippie.uiowa.edu/krause/spring2013/sbux_s13.pdf

Tashman, P., Raelin, J. (2013). Who and what really matters to the firm: Moving stakeholder salience beyond managerial perceptions. Business Ethics Quarterly. 23(4). 591-616. DOI:10.5840/beq201323441 


\section{Biographies of Authors}

Jacqueline Pena is an MBA student at Nova Southeastern University. She obtained her Bachelor's degree in Business Administration with a focus on Human Resources Management from Florida International University where she graduated with honors. Currently, Jacqueline works as an Internal Transfer Representative for Baptist Health South Florida in the HR department at South Miami Hospital.

Lucien Sintilus is an MS student in Leadership at Nova Southeastern University. He got a Bachelor degree in Anthropology/Sociology from the State University of Haiti where he was born and raised. He migrated to the United States after the earthquake destroyed this country to go back to school, get a second degree in Interdisciplinary Studies from Hodges University.

Kevin Shacket is a student of Clinical Psychology and General Business Administration at Nova Southeastern University. He completed a bachelor of general business from the University of Central Florida, and is now enrolled in the NSU Psychology program. In addition to the degree in psychology, Mr. Shacket is expanding his academic repertoire with an MBA, which he intends to use to augment his professional credentials while developing his healthcare related career. Mr. Shacket has been teaching undergraduate psychology at Broward College for the past three years. Prior to Psychology, Mr. Shacket was involved in IT and infrastructure support for a large enterprise company for six years.

Roiner Ruiz is a third year Pharm.D/MBA dual degree student. Currently, Roiner is employed as a pharmacist intern for Target. Roiner is involved in several organizations and events such as Dance Marathon which has been successful in fundraising over \$25,000 towards Joe DiMaggio's Children Hospital. In his free time, he enjoys mountain biking, snowboarding, and other outdoor activities.

Ulla Barbara Morais is an MBA student at Nova Southeastern University. In addition, she got a bachelor in Sociology of work and a Post degree in Human resources management from Portugal. She was born in Angola and raised in Portugal. Ms. Morais background experience is in Human resources management. She has an international experience by working in Portugal as a Human Resources Technician and as well as in Angola, where she worked for International Oil services companies as Human resources manager.

Yesenia Rivera is an MBA student at Nova Southeastern University. Currently, she is doing research in management, leadership, and human resources topics. She enjoys reading and staying updated on professional books in the areas of business.

Bahaudin G. Mujtaba is Professor of Management and Human Resources at the H. Wayne Huizenga School of Business and Entrepreneurship of Nova Southeastern University in Ft. Lauderdale, Florida. Bahaudin is the author and coauthor of several professional and academic books dealing with management, diversity, ethics, and business, as well as numerous academic journal articles. Bahaudin can be reached at: mujtaba@nova.edu 